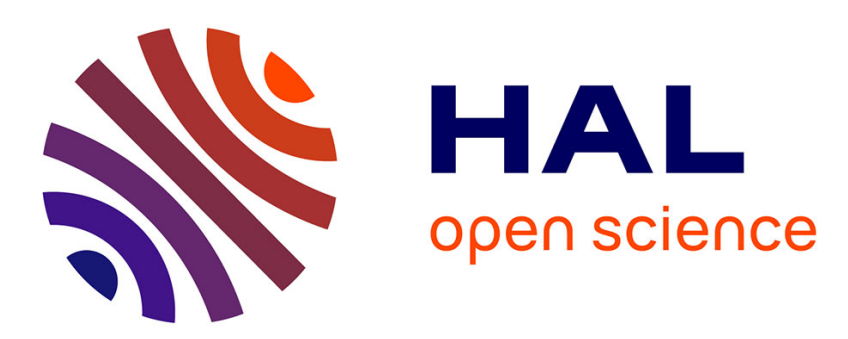

\title{
Characterisation of microstructural evolutions in refractory castables by in situ high temperature ESEM \\ H Marzagui, Thierry Cutard
}

\section{To cite this version:}

H Marzagui, Thierry Cutard. Characterisation of microstructural evolutions in refractory castables by in situ high temperature ESEM. Journal of Materials Processing Technology, 2004, 155 (2, SI), pp.1474-1481. 10.1016/j.jmatprotec.2004.04.365 . hal-01714937

\section{HAL Id: hal-01714937 \\ https://hal.science/hal-01714937}

Submitted on 6 Nov 2018

HAL is a multi-disciplinary open access archive for the deposit and dissemination of scientific research documents, whether they are published or not. The documents may come from teaching and research institutions in France or abroad, or from public or private research centers.
L'archive ouverte pluridisciplinaire HAL, est destinée au dépôt et à la diffusion de documents scientifiques de niveau recherche, publiés ou non, émanant des établissements d'enseignement et de recherche français ou étrangers, des laboratoires publics ou privés. 


\title{
Characterisation of microstructural evolutions in refractory castables by in situ high temperature ESEM
}

\author{
H. Marzagui, T. Cutard* \\ CROMeP, Ecole des Mines d'Albi, Campus Jarlard, F81000 Albi, France
}

\begin{abstract}
This paper deals with the characterisation of the microstructural evolutions during the first heating of two commercial refractory castables by dilatometry and by in situ high temperature environmental scanning electron microscopy (HT-ESEM) up to $1300^{\circ} \mathrm{C}$. Investigations have been made both on the castables and on their respective matrix. Effects of microstructural changes have been observed on dilatometric results. Four temperature domains could be defined, in which shrinkage is occurring. During in situ HT-ESEM observations, important microstructural changes could be seen in these four temperature domains. They deal first with microcrack initiation due to dehydration mechanisms. Microcrack opening then increases when increasing the sample temperature. An acceleration of these microcrack-opening mechanisms was observed when sintering starts in the $800-950^{\circ} \mathrm{C}$ temperature range. Between 1000 and $1100{ }^{\circ} \mathrm{C}$, liquid phases appear in the material and liquid phase sintering starts to occur. An increase of the liquid phase amount and of liquid phase sintering effects are observed when increasing temperature up to $1300^{\circ} \mathrm{C}$. Crystal growth was identified as occurring at this temperature too. Above $1100{ }^{\circ} \mathrm{C}$, a competition between shrinkage mechanisms and expansion ones take place. The balance between these two types of mechanisms is not the same for the two studied refractory castables.
\end{abstract}

Keywords: Refractory castables; Microstructural changes; Environmental scanning electron microscopy

\section{Introduction}

There is a trend to increase the use of unshaped refractory castables in various industries like steel-making, cement production, energy production and waste incineration. In several applications, they are more economical and easier to use than shaped refractories and they can exhibit excellent mechanical properties. Quality improvement is needed particularly to design durable parts or structures based on these materials.

One of their major characteristics is that they are fired in situ during the starting step of the industrial structure where they are used. It is known that large microstructural evolutions can take place in these refractory castables during their first heating. As they are often based on calcium-alumina cement, some studies have been made on the microstructural evolutions during the firing of calcium-alumina cement bound castables [1-4]. Dehydration, conversion of hydrates, crystallisation, sintering are known to occur in these materials when increasing the temperature. Such phase transformations often lead into damage processes by microc-

\footnotetext{
* Corresponding author.

E-mail address: cutard@enstimac.fr (T. Cutard).
}

racking and consequently to a non-linear mechanical behaviour [5]. Microsilica is generally added to improve the flaw behaviour during mixing and casting. When heating such calcium-alumina-silica cement based castables, low melting phases appear at high temperature and degrade their high temperature properties. To improve these properties, part of the cement can be substituted by superfine alumina to form an in situ mullite network that contributes to develop a strong binder phase.

Recent works have been published on the thermomechanical behaviour of unshaped refractories and on their links with microstructural evolutions [5-8]. They show a tendance to characterise them by tensile tests and compressive tests because of the large behaviour dissymetry that exists between these two solicitation modes for this material family. Results of these tests are used to identify the coefficients of constitutive equations that are implanted in finite element codes to predict the thermomechanical behaviour of industrial structures. More recently, models coupling microstructural variables and mechanical behaviour have been developed [3]. This kind of approach indicates the importance of disposing of microstructural data in a wide temperature range concerning these refractory castables.

This paper deals with results of an experimental approach developed to characterise the microstructural transforma- 
tions and damage processes, which occur in such materials during the first heating and with the help of in situ tests by dilatometry and high temperature environmental scanning electron microscopy. Two commercial refractory castables are considered and the objectives of the study are first to identify the microstructural transformations and the damage processes that occur during the first heating and to then determine their operating temperature range.

\section{Materials and experimental procedures}

Two commercial castables are considered. The first one is an ultralow cement bauxite castable (Bau-ULCC) made of bauxite aggregates, fumed silica, $\alpha$-alumina and of a calcium alumina cement. The second is a low cement andalousite castable (And-LCC) made of andalousite aggregates, fumed silica, $\alpha$-alumina and of the same calcium-alumina cement. Both materials are characterised by the same fumed silica content. In the bauxite based castable (Bau-ULCC), the $\alpha$-alumina content in two times higher than in the andalousite based one (And-LCC). Table 1 shows the chemical compositions of the castables supplied by the manufacturer. The high mismatch between the silica contents of the two materials is mainly due the high silica content in andalousite aggregates compared to bauxite ones.

The samples were prepared by mixing the raw materials with controlled water additions and finally cast in moulds under controlled vibrations and immediately wrapped in plastic. They were cured at room temperature during $24 \mathrm{~h}$ and then extracted from the moulds before a $110{ }^{\circ} \mathrm{C}-24 \mathrm{~h}$ drying step. Both castables can be considered as constituted of aggregates embedded in a matrix with particle size lower than to $200 \mu \mathrm{m}$. In order to characterise the microstructural behaviour of the matrix, samples were prepared from dry material mixtures sieved to $<200 \mu \mathrm{m}$. For dilatometry, cylinders were diamond cut at a $8 \mathrm{~mm}$ diameter and at a $25 \mathrm{~mm}$ length. Tests were performed in a $1600^{\circ} \mathrm{C}$ dilatometer (model D-DIL402C, Netzsch), under air, at $5{ }^{\circ} \mathrm{C} / \mathrm{min}$ heating and cooling rates and with $5 \mathrm{~h}$ isothermal dwells before cooling. A field emission gun environmental scanning electron microscope (model XL 30 ESEM-FEG, FEI) equipped with a $1500^{\circ} \mathrm{C}$ hot stage was used for in situ

Table 1

Chemical analysis and data of the commercial castables

\begin{tabular}{lcc}
\hline Castable type & Bau-ULCC & And-LCC \\
\hline Aggregate type & Bauxite & Andalousite \\
$\mathrm{Al}_{2} \mathrm{O}_{3}$ (wt.\%) & 85 & 58 \\
$\mathrm{SiO}_{2}$ (wt.\%) & 10 & 37.5 \\
$\mathrm{CaO}(\mathrm{wt} . \%)$ & 1.1 & 2.3 \\
$\mathrm{Fe}_{2} \mathrm{O}_{3}(\mathrm{wt} . \%)$ & 1 & 0.9 \\
$\mathrm{Maximum}$ aggregate size (mm) & 5 & 5 \\
Water requirement $(\mathrm{wt} . \%)$ & $4.2-5.2$ & $4.5-5.5$ \\
Open porosity $(\mathrm{vol} . \%)$ & 10 & 6 \\
Apparent density $\left(\mathrm{kg} / \mathrm{m}^{3}\right)$ & 2970 & 2600 \\
\hline
\end{tabular}

gaseous secondary electron imaging at high temperature (HT-ESEM images). Samples of $4 \mathrm{~mm}$ in diameter and $2 \mathrm{~mm}$ in height were diamond cut and polished before testing. Observations were performed under $\mathrm{H}_{2} \mathrm{O}$ vapour and at an operating pressure of $1.2 \mathrm{mbar}$. Heating rates was of $50{ }^{\circ} \mathrm{C} / \mathrm{min}$ and $30 \mathrm{~min}$ long isothermal dwells were programmed for image acquisition and storage.

\section{Results}

\subsection{Dilatometry}

Fig. 1 shows the dilatometric curves of the two castable matrices during a first thermal cycle up to $1300^{\circ} \mathrm{C}$. During heating, they are both characterised by a series of alternative linear expansion domains and of shrinkage domains. This indicates that these matrices do not only exhibit a thermal expansion but are subjected also to microstructural evolutions which lead to shrinkage mechanisms. Four main domains, in which such mechanisms occur, can be defined. Domain 1 , from 150 to $300{ }^{\circ} \mathrm{C}$, in which both materials are characterised by the same amplitude of shrinkage. Domain 2, between 800 and $950{ }^{\circ} \mathrm{C}$, in which the shrinkage of the Bau-ULCC matrix is of higher amplitude than that of the And-LCC matrix. Domain 3, between 1050 and $1150{ }^{\circ} \mathrm{C}$, in which a low amplitude shrinkage is observed for the Bau-ULCC matrix and no evidence of shrinkage for the And-LCC matrix. Domain 4, from 1200 up to $1300^{\circ} \mathrm{C}$, in which an high amplitude shrinkage is observed for the Bau-ULCC matrix and a change of slope is observed for the And-LCC matrix. During the $1300{ }^{\circ} \mathrm{C}$ isothermal dwells, both materials exhibit different behaviours: first a regular shrinkage followed by an expansion for the Bau-ULCC matrix and a regular expansion for the And-LCC matrix. During cooling both matrices are characterised by linear thermal contraction behaviours.

Fig. 2 shows the dilatometric behaviour of the two castables during the first heating. Both materials exhibit a thermal expansion behaviour but non-linear domains or slope

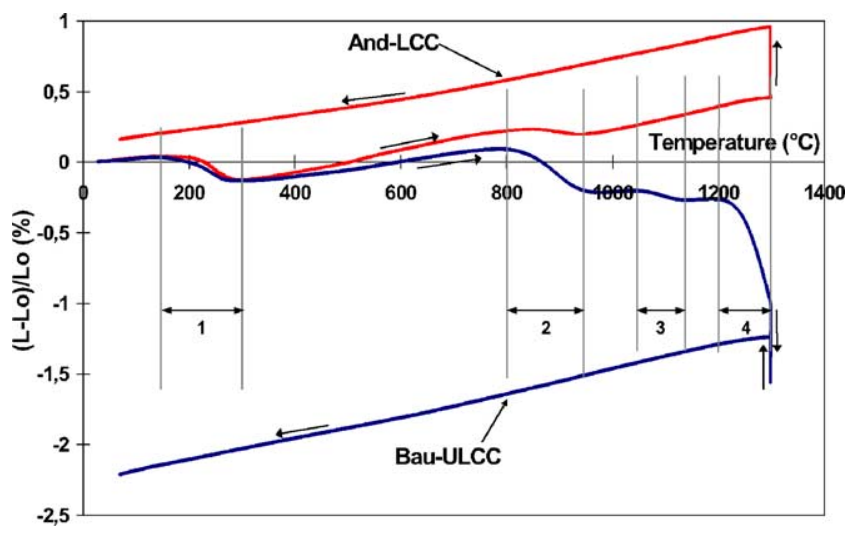

Fig. 1. Dilatometric curves of the two castable matrices during the first heating. 


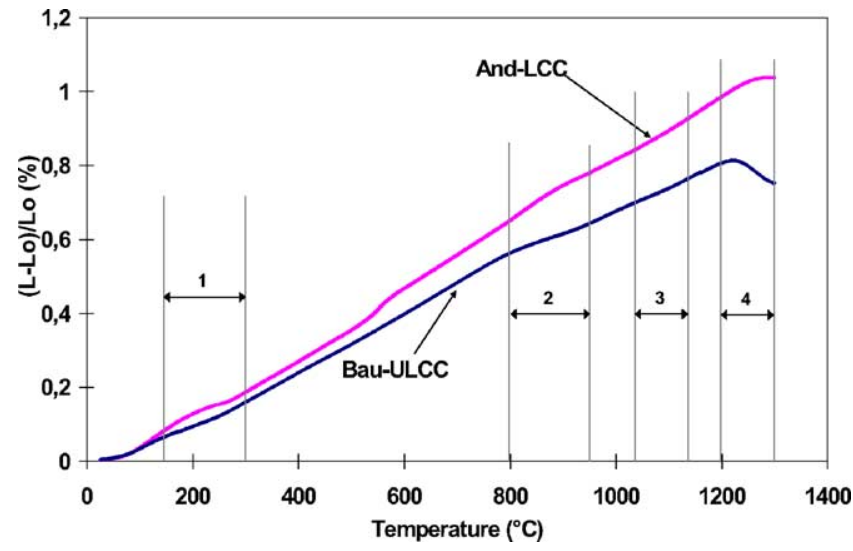

Fig. 2. Dilatometric curves of the two castables during the first heating (only relative to increasing temperature).

changes are observed. When reporting on these curves of the four precedent domains, it could be observed that the shrinkage phenomena of the two matrices have an influence on the behaviour of their respective castables, particularly in domains 1, 2 and 4. The amplitudes of shrinkage phenomena are considerably attenuated compared to the matrices.

Figs. 3 and 4 show the dilatometric curves obtained on the two matrices for several first heatings at different maximum temperatures. They allow first to observe the reproducibility

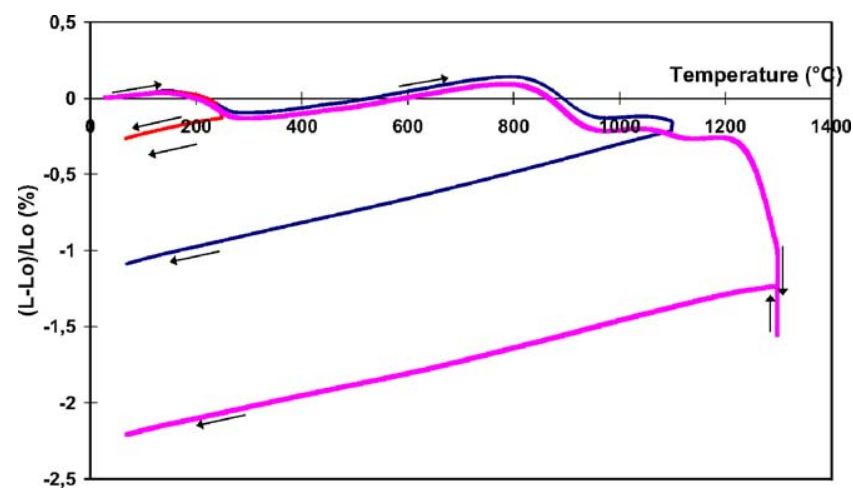

Fig. 3. Dilatometric curves of the Bau-ULCC matrix during first heatings at different temperatures.

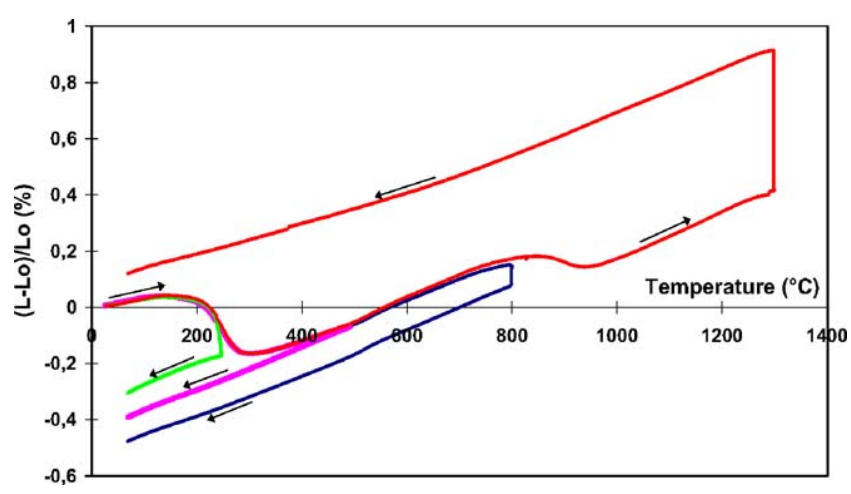

Fig. 4. Dilatometric curves of the And-LCC matrix during first heatings at different temperatures. of the dilatometric behaviour when increasing temperature. Then the irreversibility of the microstructural evolutions associated with each shrinkage domain is proved since linear thermal contraction behaviour is observed during all coolings.

\subsection{High temperature environmental scanning electron microscopy}

Fig. 5 shows the in situ HT-ESEM observations that have been made on a Bau-ULCC matrix sample during its first heating up to $1200{ }^{\circ} \mathrm{C}$. This figure clearly illustrates one type of microcracking evolution frequently observed in this material at interfaces between bauxite aggregates and matrix rich areas. Microcracks initiate in the domain $1\left(20^{\circ} \mathrm{C}<\right.$ $T<300^{\circ} \mathrm{C}$ ) and progressively open when increasing the temperature above this domain.

Fig. 6 shows the microstructural evolutions in a And-LCC matrix samples during an in situ HT-ESEM test performed up to $1400^{\circ} \mathrm{C}$. An andalousite particule or aggregate (labelled AND) and a tabular alumina aggregate (labelled A) can be seen as embedded in the binder phase. At room temperature, the microstructure was free from any microcrack. Heating up to $150{ }^{\circ} \mathrm{C}$ has led to microcrack initiation, particularly at the interfaces between the binder phase and the two types of aggregates. From 150 to $800{ }^{\circ} \mathrm{C}$, this microcracking process continues to occur by microcrack propagation and opening. Two microcracks (labelled 1 and 2 in Fig. 6) propagate through the binder phase and finally join the two aggregates. Between 800 and $1000{ }^{\circ} \mathrm{C}$, these mechanisms continue to occur and larger microcrack openings are observed both for aggregate/binder phase decohesions and for binder phase microcracks. A shrinkage of the binder phase cells, created by the microcrack network, is observed. Between 1000 and $1100{ }^{\circ} \mathrm{C}$, the morphological aspect of the microstructure changes considerably. The granular aspect of the binder phase moves to a more homogeneous one. At $1100^{\circ} \mathrm{C}$, the appearance of a liquid phase can be clearly seen and is responsible of these evolutions. This continues to occur up to $1300{ }^{\circ} \mathrm{C}$ and the amount of liquid phase appears as increasing with the temperature. Binder particules, which can be observed on the alumina aggregate at $1000^{\circ} \mathrm{C}$, have begun to convert into a liquid phase at $1100{ }^{\circ} \mathrm{C}$ and progressively form liquid droplets on the alumina surface. Furthermore a progressive closing and/or healing of microcracks 1 and 2 is observed in the $1100-1300^{\circ} \mathrm{C}$ temperature range. Since $1100{ }^{\circ} \mathrm{C}$, microporosity between the binder phase particules progressively disappears, links or bridges are created between the binder phase and aggregates, crack bridging mechanisms are observed. Those are indications of a liquid phase sintering process in the material. But local volume expansion can take part in these mechanisms too. As an example, no evidence of a decrease of the distance between the andalousite aggregate and the alumina one can be observed in this in situ HT-ESEM image series. If only densification by liquid phase sintering was responsible of 

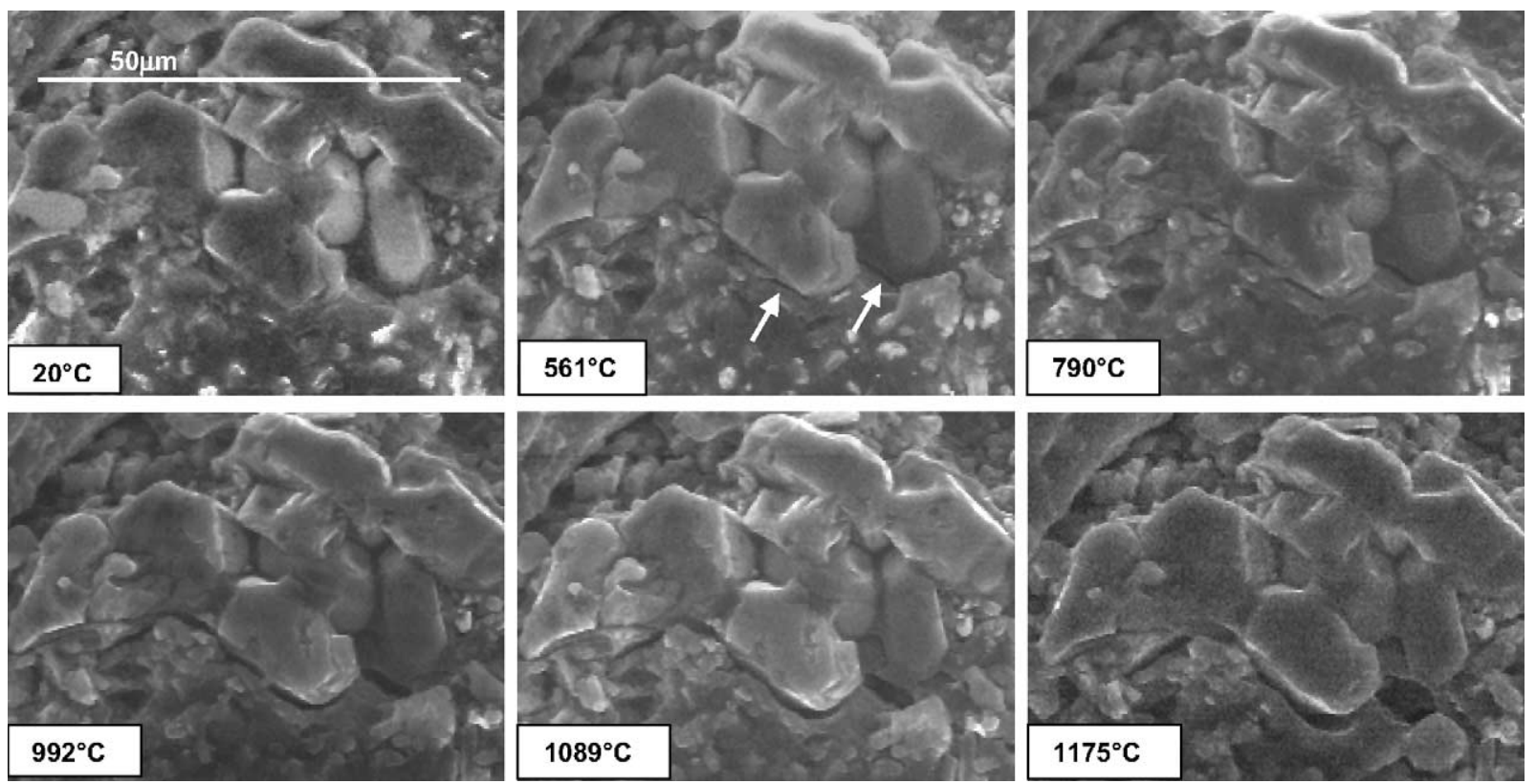

Fig. 5. In situ HT-ESEM images at different temperatures during the first heating of a Bau-ULCC matrix sample showing microcracks at aggregate/matrix interfaces and their opening when increasing the temperature.
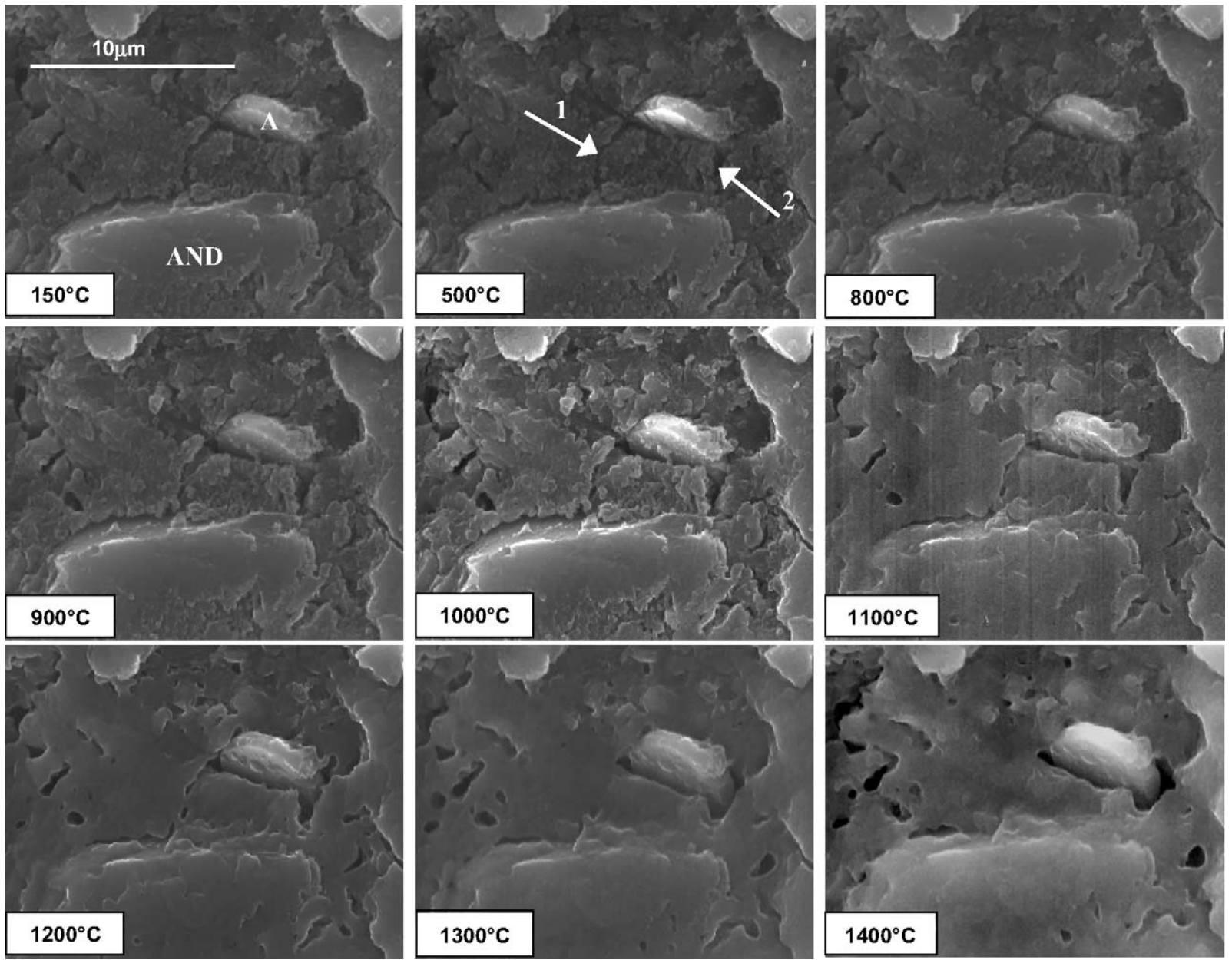

Fig. 6. In situ HT-ESEM images at different temperatures during the first heating of an And-LCC matrix sample showing microstructural evolutions (microcracking, liquid phase appearance, crystal growth and crack healing) when increasing the temperature. 

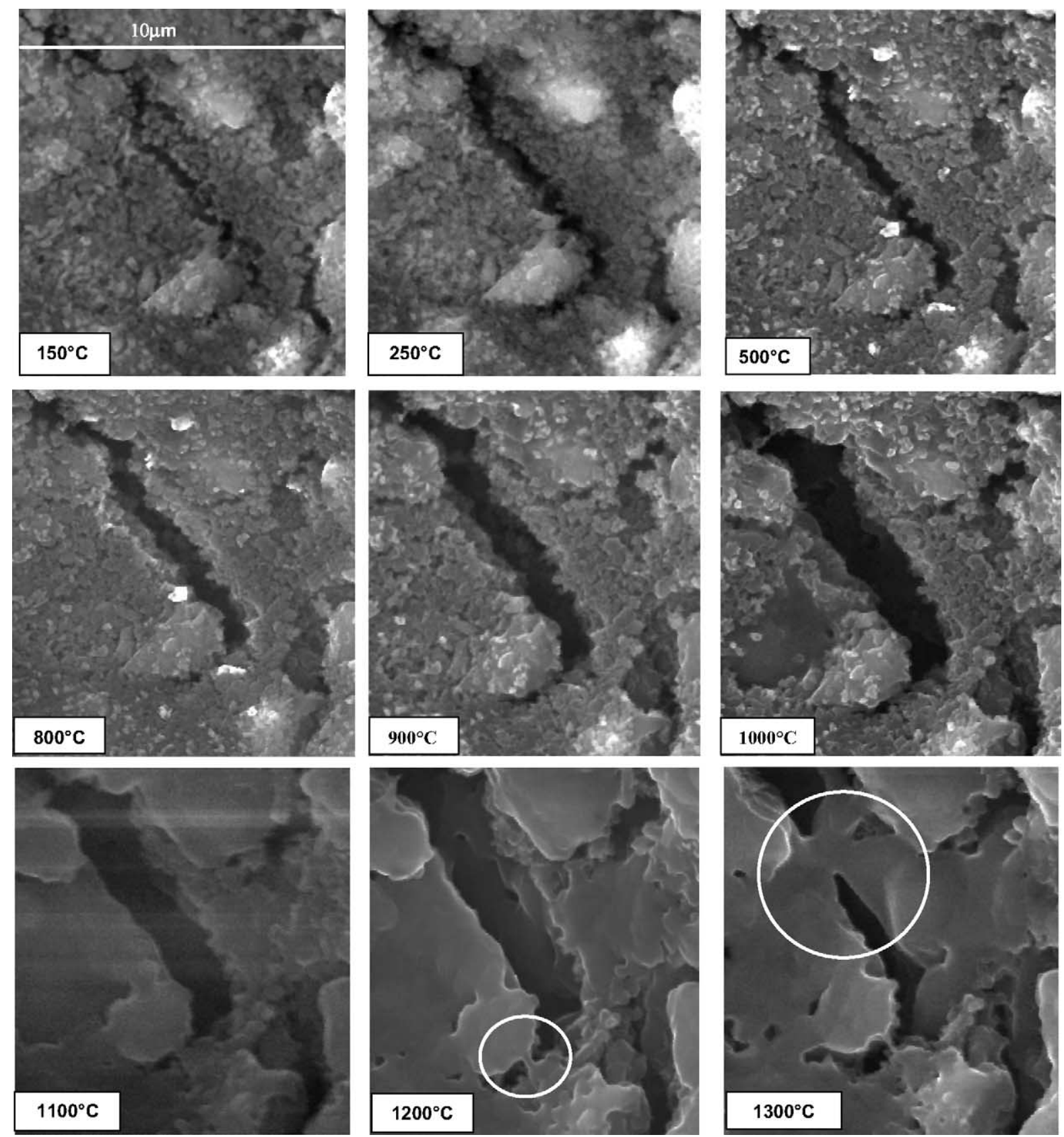

Fig. 7. High magnification in situ high temperature ESEM images at different temperatures during the first heating of an And-LCC matrix sample showing microstructural evolutions in a microcracked area.

the evolutions observed in the $1100-1300^{\circ} \mathrm{C}$ temperature range, it should be the case.

Fig. 7 shows the microstructural evolutions of another area of the same And-LCC matrix samples during the same in situ HT-ESEM test performed up to $1300^{\circ} \mathrm{C}$ but at a higher magnification. This image series focuses on the evolutions of a microcrack that has appeared at $150{ }^{\circ} \mathrm{C}$ at the surface of a $20 \mu \mathrm{m}$ in diameter porosity. A progressive microcrack opening occurs when increasing the temperature with an increase of the opening amplitude in the $900-1000{ }^{\circ} \mathrm{C}$ temperature range (see Fig. 8). Drastic microstructural changes are again observed in the $1000-1300^{\circ} \mathrm{C}$ temperature range. Since $1100^{\circ} \mathrm{C}$, a small amount of liquid phase appears and is accompanied of a progressive disappearance of the binder phase particles. The amount of liquid phase clearly increases at $1200^{\circ} \mathrm{C}$ where liquid phase bridges are observed with their characteristic incurved shape (see, for example, the circled area in Fig. $7-1200^{\circ} \mathrm{C}$ ). At $1300^{\circ} \mathrm{C}$ crack bridging is observed (see the circled area in Fig. $7-1300^{\circ} \mathrm{C}$ ). The shape of this bridge, with straight borders suggests more a crack bridging by the growth of mullite crystals rather than by liquid bridges as observed at $1200^{\circ} \mathrm{C}$. 


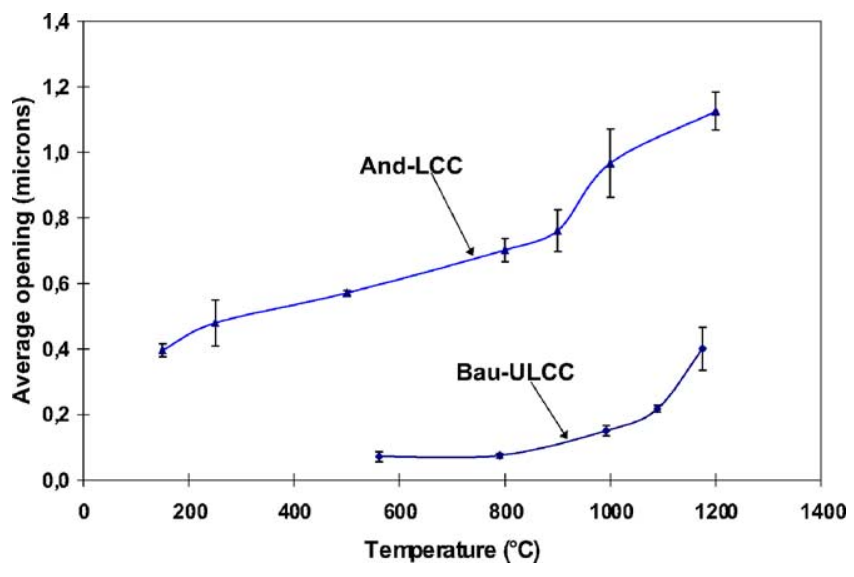

Fig. 8. Crack openings as a function of the temperature determined by digital image processing of in situ high temperature ESEM images.

\section{Discussion}

The microstructural evolutions characterised during the first heating, both by dilatometry and by in situ high temperature ESEM observations, will now be discussed by considering the four temperature domains previously defined from the matrix dilatometric curves.

In domain $1\left(150^{\circ} \mathrm{C}<T<300^{\circ} \mathrm{C}\right)$, shrinkage is observed both on the Bau-ULCC matrix and on the And-LCC curves and non-linear expansion curves characterise the two castables. High temperature ESEM observations reveal microcrack initiation, particularly at interfaces between the aggregates and the matrix. This must be related to hydrate conversion and dehydration processes that have been previously identified as operating in this temperature range $[1,3,5,9,10]$. Fig. 8 shows the evolution of microcrack openings calculated by digital image processing of ESEM images for the two matrices. It can be clearly seen that microcrack opening increases when the temperature increases.

Between domains 1 and 2, dehydration process generally continue to occur. They can be responsible of the slightly non-linear expansion behaviour observed in this temperature range.

In domain $2\left(800^{\circ} \mathrm{C}<T<950{ }^{\circ} \mathrm{C}\right)$, the two matrices are characterised by shrinkage, which is more pronounced for the Bau-ULCC one. For the two castables, non-linear expansion curves are observed again. In this domain 2, there is a direct correlation between the shrinkage measured by dilatometry and the acceleration of the dependence of microcrack opening as a function of temperature (see Fig. 8). Evidence of shrinkage was observed for the binder phase cells created by the microcrack network too. The differential thermal expansions between aggregates and matrix can be considered as responsible again. In this temperature domain, sintering starts to occur in the matrix while aggregates continue to expand. Nonnet et al. [1] have already observed a sintering start in CA or CAS cement based castables since $900{ }^{\circ} \mathrm{C}$.
In domain $3\left(1050^{\circ} \mathrm{C}<T<1150^{\circ} \mathrm{C}\right)$, a low amplitude shrinkage is measured by dilatometry on the Bau-ULCC matrix and no evidence of shrinkage could be detected on the three other materials (And-LCC matrix, Bau-ULCC and And-LCC castables). Drastic changes could be observed in the microstructure of the Bau-ULCC and And-LCC matrix with the help of in situ high temperature ESEM observations. They consist in liquid phase appearance and in a disappearance of the granular aspect and of the microporosity of the binder phase. In this temperature domain, a liquid phase sintering starts to occur in both materials. Presence of microsilica in CA cements is known to lead to liquid formation via low melting phases in the CAS system at such temperatures [3]. Furthermore, similar shrinkage mechanisms have been observed by Nonnet et al in a CAS cement based castable [1]. The crystallisation of $\mathrm{CA}_{2}$ as the product of a reaction between CA and alumina is known to occur in this temperature range too and to lead to a relative expansion volume of $13.6 \%$ [5]. Thus there is so a competition between two phenomena: expansion due to the formation of $\mathrm{CA}_{2}$ and shrinkage related to sintering. In the Bau-ULCC matrix, sintering effects are dominant since shrinkage is measured by dilatometry. In the And-LCC matrix evidence of sintering mechanisms are observed on in situ ESEM images but no shrinkage is measured by dilatometry. This indicates that the two competitive effects annuled each other leading to a linear dilatometric behaviour. The same comments can be done on the two castables, which are both characterised by a linear dilatometric behaviour in this temperature domain. In spite of this dilatometric linear behaviour with could suggest a microstructural stability, drastic microstructural changes take place in the material.

In domain $4\left(1200{ }^{\circ} \mathrm{C}<T<1300{ }^{\circ} \mathrm{C}\right)$, a high amplitude shrinkage is observed for the Bau-ULCC matrix and a only slight deviation from a linear expansion for the And-LCC matrix. It must be remembered that these matrix have different behaviours during the $1300{ }^{\circ} \mathrm{C}$ isothermal dwell. The Bau-ULCC one first exhibits a shrinkage before switching to expansion. The And-LCC one is characterised by an expansion behaviour all along the dwell. In situ ESEM observations allow to observe large amount of liquid phase in the two matrices. Fig. 9 shows an illustration of a liquid phase formation in domains 3 and 4 in a And-LCC matrix sample. At $1000^{\circ} \mathrm{C}$, small matrix particles are visible on an alumina tablet. At $1100{ }^{\circ} \mathrm{C}$, liquid phase starts from these particules. Complete fusion of these particles is observed at 1200 and $1300^{\circ} \mathrm{C}$ where liquid droplets are clearly seen. Their shape indicates the good wetting behaviour between the liquid phase and alumina. Furthermore, a coalescence of droplets is observed when increasing the temperature that indicates a viscosity decrease of this liquid phase. Liquid phase sintering mechanisms are clearly active in this temperature domain. These in situ observations confirm hypothesis of liquid phase sintering previously given to explain results on CAS cement based castables [3,4]. Since $1300^{\circ} \mathrm{C}$ crystal growth is observed, particularly in the And-LCC matrix. 


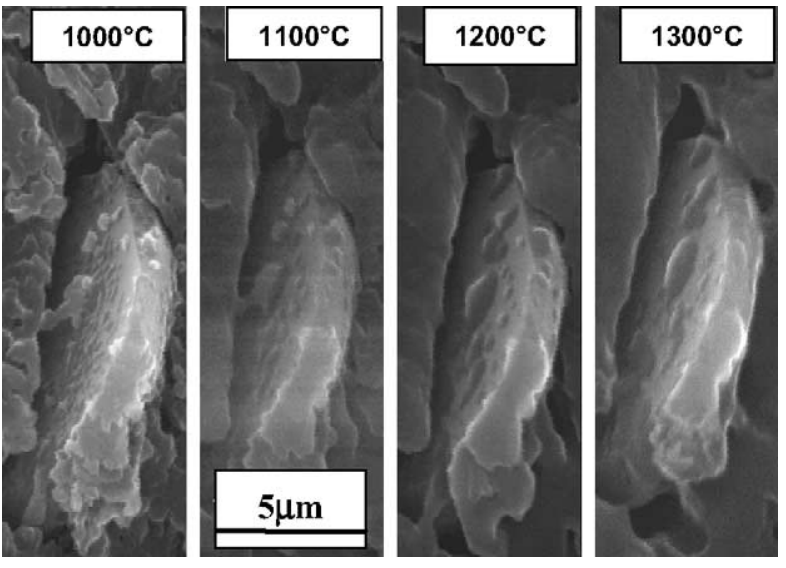

Fig. 9. High magnification and high temperature ESEM images showing liquid phase appearance during the first heating in an And-LCC matrix sample.

Because of their shape they are expected to be mullite crystals. This hypothesis is reinforced by the results of X-ray diffraction tests performed on the series of And-LCC matrix samples heated at different temperatures. They indicate the appearance of mullite when the temperature is greater or equal to $1300^{\circ} \mathrm{C}$. In this And-LCC matrix, mullite can form either from the andalousite particles or from a reaction between superfine alumina and fumed silica. In the Bau-ULCC matrix, only the second mechanism can occur. The competition between shrinkage mechanisms and expansion ones continues to occur in this temperature domain. The shrinkage ones remain dominant in the Bau-ULCC material and the expansion ones in the And-LCC material. In the two materials, microcrack healing is observed and can be related to the two types of mechanisms. On the one hand those are liquid phase sintering mechanisms that are active in microcrack healing, and on the other hand those are formations of $\mathrm{CA}_{2}$ and of mullite.

\section{Conclusion}

Characterisation of the microstructural evolutions during first heatings of two commercial refractory castables (a bauxite based one and an andalousite based one) has been done by dilatometry and in situ high temperature environmental scanning electron microscopy up to $1300{ }^{\circ} \mathrm{C}$. Investigations have been made both on the castables and on their respective matrices sieved at $200 \mu \mathrm{m}$. Effects of microstructural changes have been observed by dilatometry with alternative linear expansion domains and shrinkage ones. Four temperature domains, in which shrinkage is occurring, could be defined. A good agreement was obtained between results of dilatometry and of in situ HT-ESEM observations. Important microstructural changes could be seen in these four temperature domains. They deal first with microcrack initiation in the $150-300{ }^{\circ} \mathrm{C}$ temperature range due to dehydration mechanisms. Then microcrack opening increases when increasing the sample temperature. An acceleration of these microcrack-opening mechanisms was observed when sintering starts, in the $800-950{ }^{\circ} \mathrm{C}$ temperature range. Between 1050 and $1150{ }^{\circ} \mathrm{C}$, liquid phases appear in the material and liquid phase sintering starts to occur. An increase of the liquid phase amount and of liquid phase sintering effects are observed when increasing the temperature up to $1300^{\circ} \mathrm{C}$. Crystal growth was identified as occurring at this temperature too. Above $1100{ }^{\circ} \mathrm{C}$, a competition between shrinkage mechanisms and expansion ones take place. The balance between these two types of mechanisms is not the same for the two studied refractory castables. In situ HT-ESEM observations appear as well suited to follow the microstructural evolutions in refractory castables during thermal cycles.

The complementary between dilatometry and in situ HT-ESEM observations has been seen. As an example, linear dilatometric behaviours have been measured that could suggest a thermal expansion and a microstructure stability. Furthermore, in the same temperature domain, drastic microstructural evolutions have been observed by in situ HT-ESEM. In such cases, the apparent linear dilatometric behaviour is the result of the competition between several mechanisms.

For this type of materials, results of such experiments are useful for a better understanding of their microstructural behaviour and of its influence on the thermomechanical behaviour.

\section{Acknowledgements}

This work is made in the field of a French research program (PROMETHEREF) for improving the knowledge of thermal and mechanical properties of industrial refractories, involving three industrial partners and five public research laboratories. Authors wish to thank the French Ministry of Industry (Michel Mussino), TRB (Nicolas Prompt, Thierry Joly) and EDF (Patrick Billard, Yves Dutheillet) for their technical and financial support in this program, and Michel Boussuge, coordinator of the program (Centre Pierre Marie Fourt, Ecole des Mines de Paris) for helpful discussions. Authors wish to thank Serge Tovar and Aurélien Mazzoni for their implication in high temperature ESEM observations too.

\section{References}

[1] E. Nonnet, N. Lequeux, P. Boch, Elastic properties of high alumina cement castables from room temperature to $1600{ }^{\circ} \mathrm{C}$, J. Eur. Ceram. Soc. 19 (8) (1999) 1575-1583.

[2] N. Schmitt, J.-F. Hernandez, V. Lamour, Y. Berthaud, P. Meunier, J. Poirier, Coupling between kinetics of dehydration, physical and mechanical behaviour for high alumina castable, Cement Concr. Res. 30 (10) (2000) 1597-1607.

[3] H. Sarpoolaky, K.G. Ahari, W.E. Lee, Influence of in situ phase formation on microstructural evolution and properties of castable refractories, Ceram. Int. 28 (5) (2002) 487-493. 
[4] F. Simonin, C. Olagnon, S. Maximilien, G. Fantozzi, Thermomechanical behavior of high-alumina refractory castables with synthetic spinel additions, J. Am. Ceram. Soc. 83 (10) (2000) 24812490 .

[5] F. Simonin, C. Olagnon, S. Maximilien, G. Fantozzi, Room temperature quasi-brittle behaviour of an aluminous refractory concrete after firing, J. Eur. Ceram. Soc. 22 (2) (2002) 165-172.

[6] I.A. Altun, Effect of temperature on the mechanical properties of self-flowing low cement refractory concrete, Cement Concr. Res. 31 (8) (2001) 1233-1237.
[7] J.M. Robin, Y. Berthaud, N. Schmitt, J. Poirier, D. Themines, Thermomechanical behaviour of magnesia-carbon refractories, Brit. Ceram. Trans. 97 (1) 1998.

[8] N. Schmitt, Y. Berthaud, J. Poirier, Tensile behaviour of magnesia carbon refractories, J. Eur. Ceram. Soc. 20 (2000) 2239-2248.

[9] F. Guirado, S. Galí, J.S. Chinchón, Thermal decomposition of hydrated alumina cement $\left(\mathrm{CAH}_{10}\right)$, Cement Concr. Res. 28 (3) (1998) 381-390

[10] K.M. Parker, J.H. Sharp, Refractory calcium aluminate cements, Trans. J. Brit. Ceram. Soc. 81 (2) (1982) 35-42. 